\title{
Rainfall-Runoff Modelling Using Artificial Neural Networks (ANNs) Model
}

\author{
Ashish Krishna Yadav*, Veerendra Kumar Chandola, \\ Abhishek Singh and Bhaskar Pratap Singh
}

Department of Farm Engineering, Institute of Agricultural Sciences, Banaras Hindu

University, Varanasi-221005, Uttar Pradesh, India

*Corresponding author

\section{Ke yw ords \\ Artificial Neural Networks (ANNs), \\ Sum of squares error (SSE), Relative error (RE) \\ Article Info \\ Accepted: \\ 05 February 2020 \\ Available Online: \\ 10 March 2020}

\section{A B S T R A C T}

Water resource assessment involved various variables that can be simplified and tackled by developing a suitable mathematical model. Rainfall-Runoff (RR) modeling considered as a major hydrologic process and is essential for water resources management. This study presents the development of rainfall-runoff model based on artificial neural networks (ANNs) models in Shipra river basin of Madhya Pradesh. The ability of model was evaluated based on sum of squares error (SSE) and relative error. The Sum of squares error obtained during this study was 30.525 in training and 53.076 in testing and the Relative error value obtained was 0.939 in training and 0.874 in testing at Mahidpur station but at Ujjain station, the SSE obtained during this study was found to be 30.488during training and 10.703during testing while the relative error value obtained was 0.938 in training and 0.915 in testing. The model was found suitable for simulating hydrological response of the basin to the rainfall and predicting daily runoff with high degree of accuracy. The study demonstrates the applicability of ANN approach using the statistical tool SPSS 16.0 in developing effective non-linear models of rainfall-runoff process in order to represent the internal hydrologic structure of the watershed.

\section{Introduction}

We need to study the basin response to the catchment rainfall for water resource planning of a basin. This requires development of a relationship between basin rainfall and runoff. Most of river catchments in India are ungauged and generally the limited discharge data are available with the concern state and central agencies. Under such circumstance's rainfall-runoff model can be developed to simulate the natural hydrological processes to estimate the runoff from the catchment. A rainfall-runoff model is a mathematical 
representation describing the rainfall-runoff relations of a catchment area or a watershed. More precisely, it produces the surface runoff hydrograph as a response to a rainfall as an input. Rainfall-runoff models are classified as deterministic, stochastic, conceptual, theoretical, black box, continuous event, complete, routing or simplified (Linsley, 1982). The widely known rainfall-runoff models identified are the rational method (Mcpherson, 1969), Soil Conservation Services (SCS) Curve Number method (Maidment, 1993), and Green-Ampt method (Green and Ampt, 1911). Nash (1958) considered watershed as a series of identical reservoirs and prepared a conceptual rainfallrunoff models by routing a unit inflow through the reservoirs. Kumbhare and Rastogi (1984) tested the Nash conceptual model (1958) and found that runoff was generated in good agreement with actual runoff hydrograph. Kumar and Rastogi (1989) developed a mathematical model of the instantaneous unit hydrograph based on time area histogram for a small watershed at Pantnagar. Now-a-days, artificial neural networks (ANN) have found increasing applications in various aspects of hydrology. ANN approach is faster compared with its conventional compatriots, robust in noisy environments, flexible in the range of problems it can solve, and highly adaptive to the newer environments. Data-driven black box models such as ANNs are preferred alternatives for systems in which different mechanisms impact each other and precise identification of the interactions among all these mechanisms is not possible. Being an example for such systems, river flow has been modeled by ANNs extensively: Karunanithi et al., (1994), Smith and Eli (1995), Thirumalaiah and Deo (1998), Tokar and Johnson (1999), Agarwal and Singh (2004), Garbrecht (2006) etc. Neural networks can be thought of as computational patterns searching and matching procedures that permit forecasting without an intimate knowledge of the underlying physical or chemical processes. Rainfall-runoff modeling took advantage of this fact and ANN has been applied to model the rainfall-runoff relationship of different scale systems (Hall and Minns, 1993; Zealand et al., 1999). Recent studies through ANN (Singh et al., 2015; Srivastava et al., 2017) showed the applicability of ANN on rainfall forecasting. In a further study Singh et al., (2017) estimated the monsoon season rainfall and conducted the sensitivity analysis of different weather factors affecting the monsoon rainfall. The suitability of ANN is proved by different researchers (Saran et al., 2017; Singh et al., 2016; Singh et al., 2018). The present study examines application of the ANN to model the runoff process in the Shipra river basin in Malwa region of Western Madhya Pradesh. In this study, ANN feed forward back propagation algorithm has been used to model the daily rainfall-runoff relationship in the Shipra basin of Malwa region in Madhya Pradesh, India.

\section{Materials and Methods}

\section{Study area: location and brief description}

Shipra is one of the important rivers of Malwa region in Western Madhya Pradesh. Shipra river basin has been extended between $76^{\circ} 06^{\prime}$ $20^{\prime \prime}$ and $75^{\circ} 55^{\prime} 60^{\prime \prime}$ North Latitude and $22^{\circ}$ $97^{\prime} 00^{\prime \prime}$ 'and $23^{\circ} 76^{\prime} 20^{\prime \prime}$ 'East Longitude and it covers an area of $5612 \mathrm{~km}^{2}$.It originates from Kakribardi hills in Vindhya Range north of Dhar and flows north across the Malwa Plateau to join the Chambal River. It has two main tributaries, Gambhir and Khan river. Khan confluences with Shipra near Ujjain and Gambhir confluences near Mahidpur. Over the years the river has lost its perennial nature and now runs dry for a period of 5 to 6 months per year. The water of the Shipra is used for drinking, industrial use and lift irrigation purposes. The index map of Shiprais shown in fig. no. 1 . 
The river traverses' total course of about 190 $\mathrm{km}$ through four districts namely Dewas, Indore, Ujjain, and Ratlam before joining Chambal river near Kalu-Kher village. The majority of the Shipra basin area falls in Indore and Ujjain districts however small part come under Ratlam and Dewas districts.

\section{Data used}

\section{Meteorological data: rainfall data}

The daily rainfall data from 1989-2007 for monsoon season (June to October) of two rain gauge stations, namely Mahidpur and Ujjain falling in and around Shipra river basin, has been collected from State Water Data Centre, Water Resources Department, Bhopal, Govt. of Madhya Pradesh. Some rainfall data were also collected from $\mathrm{O} / \mathrm{o}$ Superintendent of Land Records Ujjain.

\section{Hydrological data: gauge-discharge data}

The ten-daily gauge-discharge data for monsoon season (1989-2007) at Ujjain and Mahidpursites on Shiprariver was collected from regional center, National Institute of Hydrology, Bhopal.

\section{Statistical analysis}

The various statistical properties evaluated in this study are given below:

\section{Arithmetic mean}

Arithmetic mean is the measure of central tendency of the given data. The following formulae have been used for computing arithmetic mean:

$$
\bar{X}=\sum_{i}^{n} \frac{X_{i}}{N}
$$

Where, $\bar{X}=$ Arithmetic mean of given data

$$
\mathrm{X}_{\mathrm{i}}=\text { Rainfall data }
$$

$$
\mathrm{N}=\quad \text { Total number of rainfall data }
$$

\section{Variability}

The variability of any data series is evaluated based on the standard deviation which is the square root of the mean square deviation is the standard deviation. The following formula has been used for computation of standard deviation:

$$
\sigma={\sqrt{\frac{\sum\left(x-\bar{x}^{2}\right.}{N-1}}}^{2}
$$

Where, $\sigma=$ Standard deviation

$\bar{x}=\quad$ Mean of the rainfall data

$\mathrm{N}=\quad$ Total no. of rainfall data

\section{Relative error}

Mathematically, relative error can be defined as the ratio of measured value minus actual value to the actual value.

Relative error $(\mathrm{RE})=$

(Measured value - Actual value) / Actual value ... (3)

\section{Sum of square error}

It is a measure of the discrepancy between the data and an estimation model. A small RSS indicates a tight fit of the model to the data. It is used as an optimality criterion in parameter selection and model selection.

Mathematically,

$\mathrm{SSE}=\sum\left(\mathrm{n}_{\mathrm{j}}-1\right) \mathrm{s}_{\mathrm{j}}^{2}$

Where,

$\mathrm{SSE}$ is sum of squared error, $n_{j}$ is size of 
sample from population $\mathrm{j}$ and $\mathrm{s}_{\mathrm{j}}=$ variance of sample from population $\mathrm{j}$

\section{Multilayered feed forward networks}

The multi-layered feed forward network is shown in Fig. 2.This structure is called multilayer because it has a layer of processing units (i.e., the hidden units) in addition to the output units. These networks are called feed forward because the output from one layer of neurons feeds forward into the next layer of neurons. There are never any backward connections, and connections never skip a layer. A multilayer feed forward neural network consists of a layer of input units, one or more layers of hidden units, and one output layer of units. A "neuron" in a neural network is sometimes called a "node" or "unit"; all these terms mean the same thing, and are interchangeable. A neural network that has no hidden units is called a perceptron. However, a perceptron can only represent linear functions, so it isn't powerful enough for hydrological applications.

A feed forward neural network was fitted to the rainfall data of Mahidpur and Ujjain with the help of SPSS 16.0, where the value of the same day rainfall and rainfall at $1^{\text {st }}$ lag were taken for forecasting. The data was divided into two sets as Training and Testing. Out of the available data $69.5 \%$ data was taken for training and remaining $30.5 \%$ data was used for testing in both the rain gauge stations in the Shipra river basin as shown in Table 1.

\section{Results and Discussion}

\section{Statistical analysis}

The statistical analysis of rainfall in the study area has been carried out using 18 years rainfall data of five rain-gauge stations namely Ujjain, and Mahidpur. The average annual and seasonal rainfall in the basin were observed to be $932 \mathrm{~mm}$ and $890 \mathrm{~mm}$, respectively. The standard deviation varied from 236 to $389 \mathrm{~mm}$. Based on the analysis it was found that the rainfall of Shipra River basin has very high temporal variation and moderate spatial variation. The statistical information derived from rainfall data is shown in Table 2.

The mean monthly rainfall distribution in the study area is shown in the Figure 3.

Table.1 ANN case processing summary of Runoff for both Mahidpur station and Ujjain station in Shipra River basin

\begin{tabular}{|c|l|l|c|c|}
\hline & & & N & Percent \\
\hline $\mathbf{1}$ & Sample & Training & 66 & 69.5 \\
\hline $\mathbf{2}$ & & Testing & 29 & 30.5 \\
\hline $\mathbf{3}$ & Valid & & 95 & 100 \\
\hline $\mathbf{4}$ & Total & & 95 & 100 \\
\hline
\end{tabular}

Table.2 Statistical analysis of annual rainfall of Shipra River Basin

\begin{tabular}{|c|c|c|}
\hline Item & Mahidpur & Ujjain \\
\hline Average Annual Rainfall (mm) & 890 & 1013 \\
\hline Average Seasonal Rainfall (mm) & 838 & 950 \\
\hline Standard Deviation (mm) & 306 & 389 \\
\hline Maximum Rainfall (mm) & 165 & 2071 \\
\hline Minimum Rainfall (mm) & 539 & 559 \\
\hline
\end{tabular}


Table.3 Training summary and fit statistics of ANN for rainfall- runoff model for Mahidpur station

\begin{tabular}{|l|l|l|}
\hline Training & Sum of Squares Error & $\mathbf{3 0 . 5 2 5}$ \\
\cline { 2 - 3 } & Relative Error & .939 \\
\cline { 2 - 3 } & Stopping Rule Used & $\begin{array}{l}\text { Relative change in training error } \\
\text { criterion }(.0001) \text { achieved }\end{array}$ \\
\cline { 2 - 3 } Testing & Training Time & $00: 00: 00: 005$ \\
\hline & Sum of Squares Error & 53.076 \\
\hline & Relative Error & .874 \\
\hline
\end{tabular}

Table.4 Training summary and fit statistics of ANN for rainfall- runoff model for Ujjain station

\begin{tabular}{|l|l|l|}
\hline Training & Sum of Squares Error & $\mathbf{3 0 . 4 8 8}$ \\
\hline & Relative Error & .938 \\
\hline & Stopping Rule Used & $\begin{array}{l}\text { Relative change in training error } \\
\text { criterion }(.0001) \text { achieved }\end{array}$ \\
\hline & Training Time & $00: 00: 00: 018$ \\
\hline \multirow{2}{*}{ Testing } & Sum of Squares Error & 10.703 \\
\cline { 2 - 3 } & Relative Error & .915 \\
\hline
\end{tabular}

Fig.1 Index map of Shipra river basin

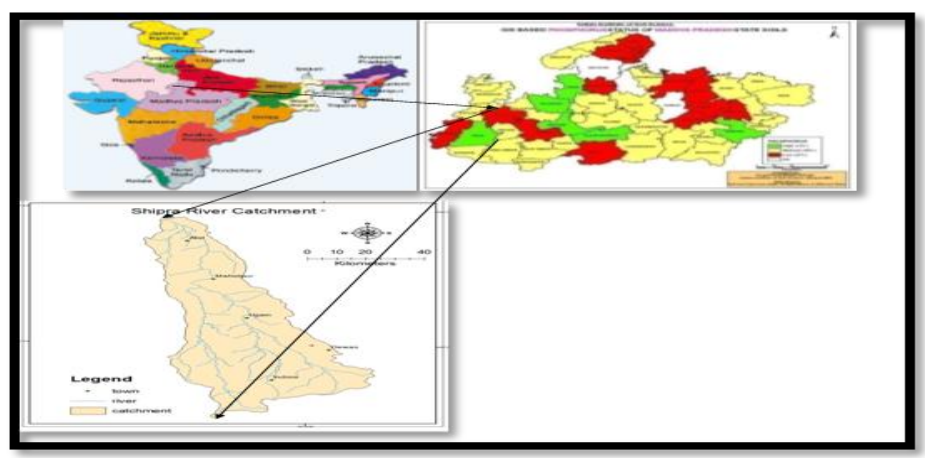

Fig.2 Feed-forward architecture with one hidden layer



Input layer Hidden layer Output layer 
Fig.3 Mean monthly rainfall distribution in Shipra River basin

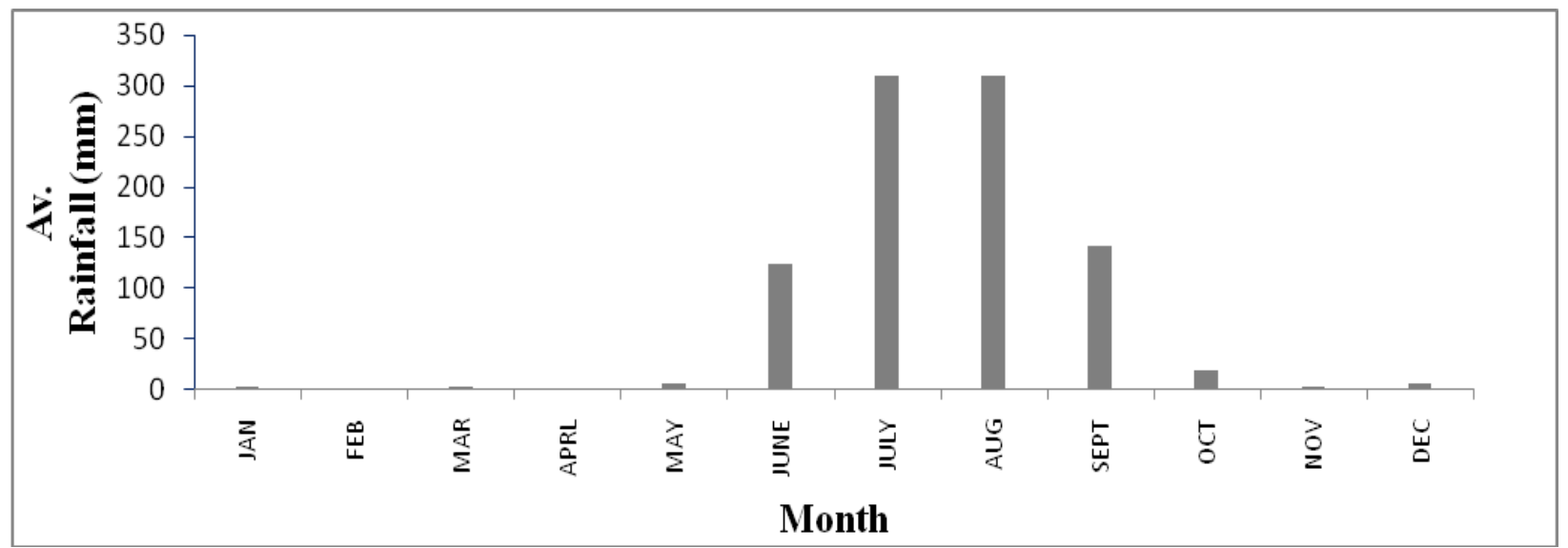

Fig.4 The architecture of network fitted to the rainfall and runoff data for

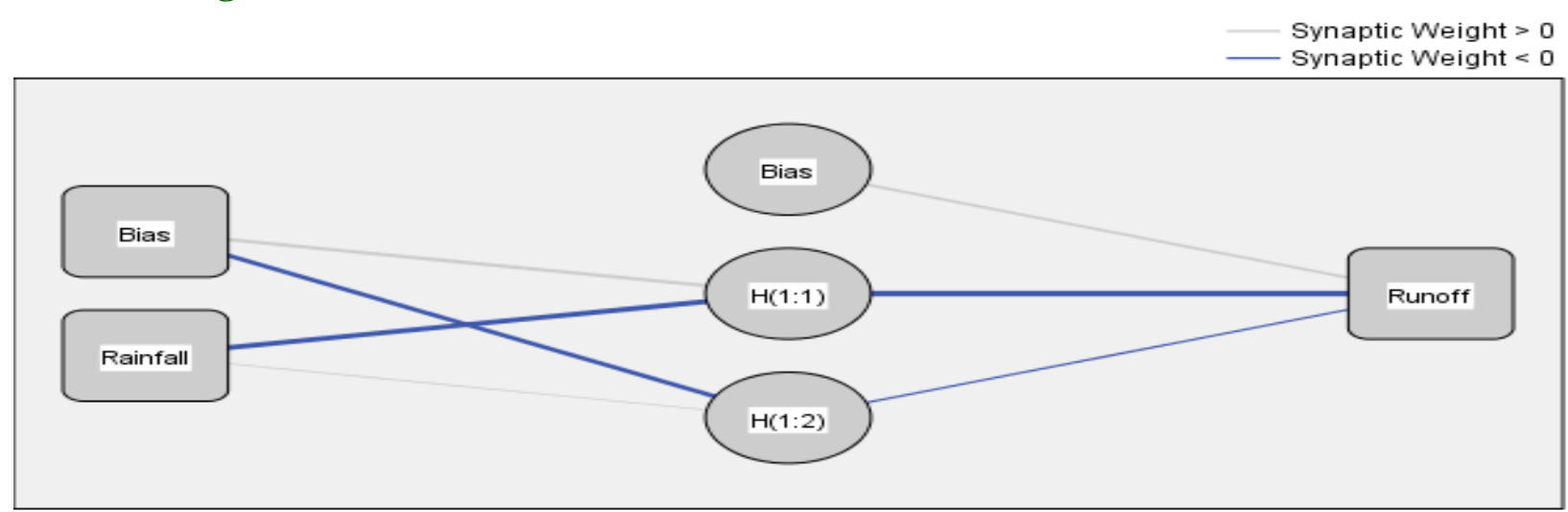

Hidden layer activation function: Hyperbolic tangent

Output layer activation function: Identity

Fig.5 The architecture of network fitted to the rainfall and runoff data for Ujjain station.

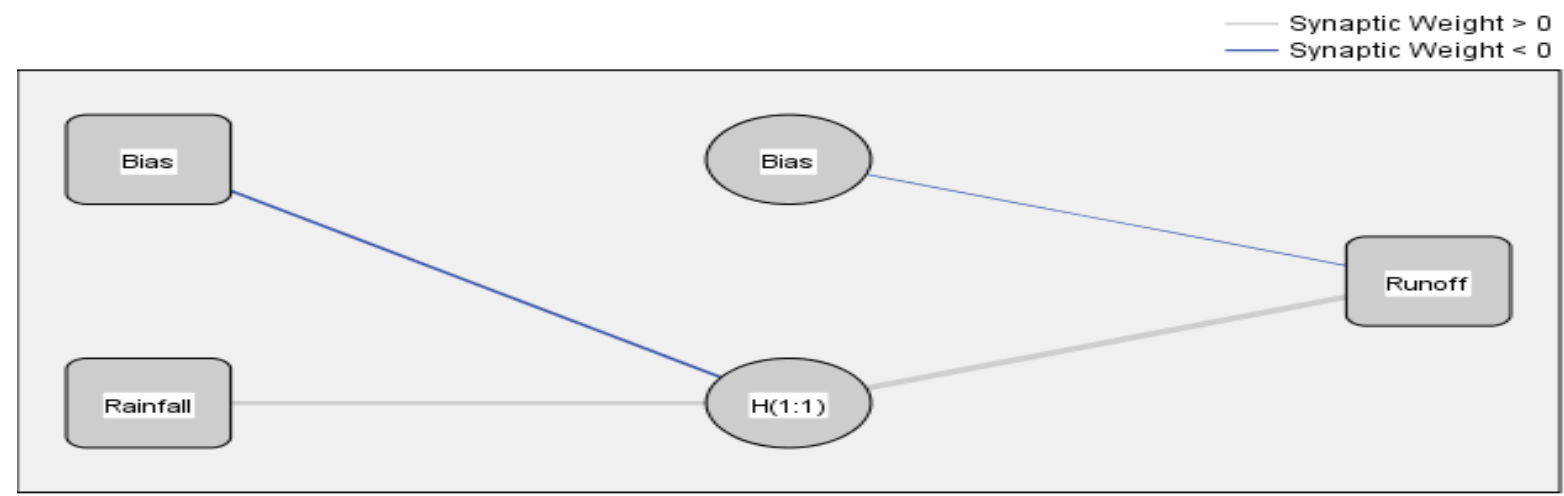

Hidden layer activation function: Hyperbolic tangent

Output layer activation function: Identity 
Fig.6 Observed Vs predicted runoff graph for Mahidpur station

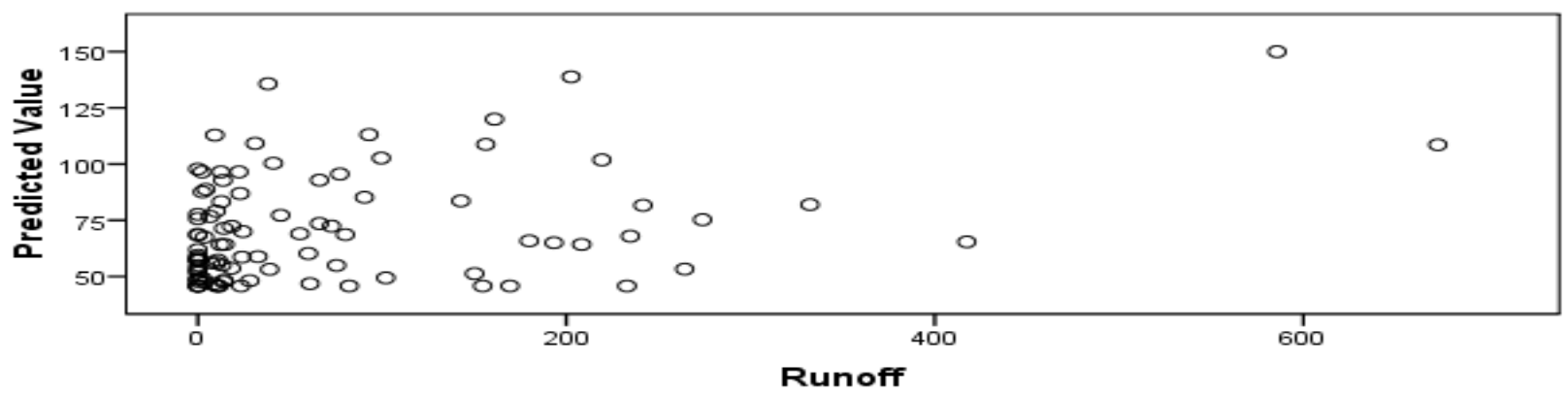

Fig.7 Observed Vs predicted runoff graph for Ujjain station

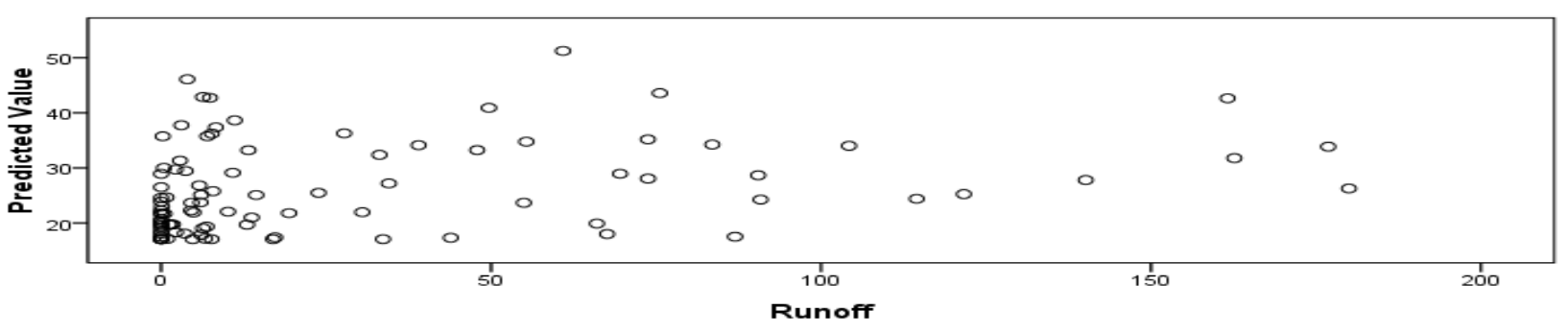

Fig.8 Residual vs the predicted runoff graph for Mahidpur station

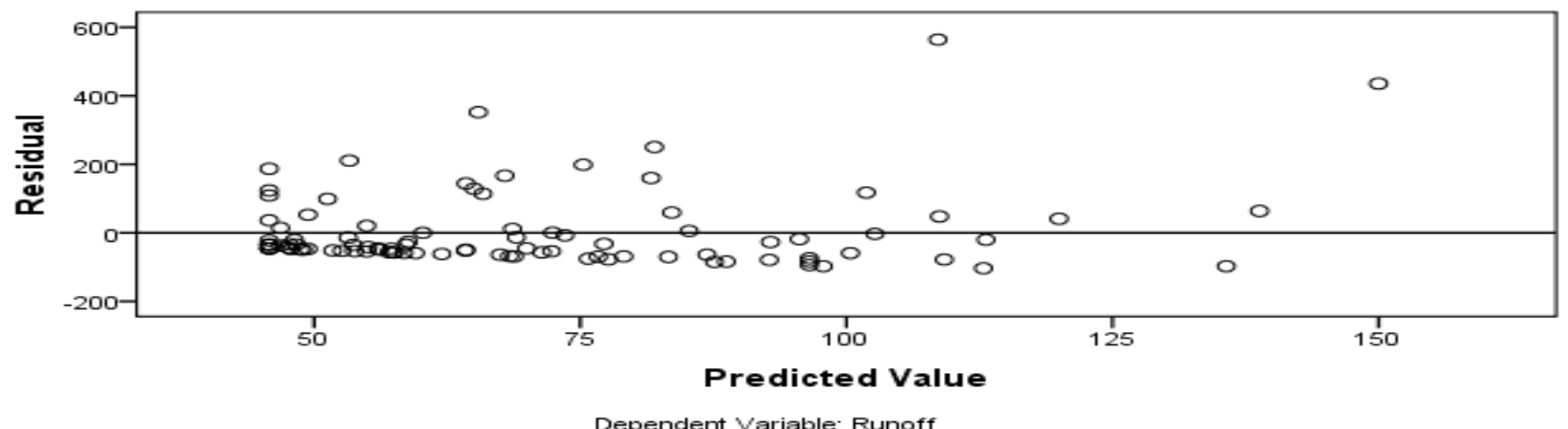

Fig.9 Residual vs the predicted runoff graph for Ujjain station at Shipra basin

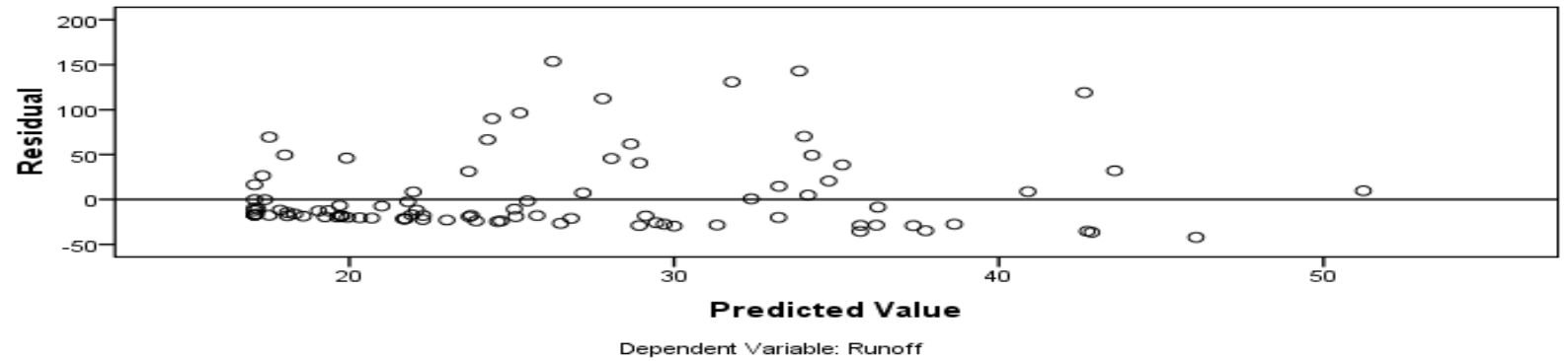


Rainfall-Runoff modeling using ANN by taking rainfall as a input

The architecture of network for both stations, Mahidpur and Ujjain have been shown in Fig. 4 and Fig. 5 respectively. In both figures, light colour lines shows the weights greater than zero and dark colour lines shows weight less than zero. The figure indicates that the network has an input layer, a single hidden layer and a output layer. In hidden layer there are two units and the activation function used is hyperbolic tangent.

The training summary and the fit statistics for the training and testing for Mahidpur and Ujjain station are given in Table 3 and Table 4 respectively. For Mahidpur station, during training portion of the data the relative error was 0.939 and, in the testing set it was reduced to 0.874 whereas in Ujjain this was analyzed 0.938 in training and deducted to 0.915 during training.

The observed vs the predicted graph has been depicted in Fig. 6 and Fig. 7 and indicated that except for few outlines it is a straight line. It indicates almost one to one correspondence among the observed and predicted values, however due to some outliers it is not fairly linear at both stations.

The residual vs predicted graph for both stations, i.e. Mahidpur and Ujjain illustrated in Fig. 8 and Fig. 9 respectively also shows that the residual does not follow a definite pattern and therefore are not correlated, however there are some outliers. If there is no dependence among the residuals then we can regard them as observations of independent random variables and believe that ANN satisfactory.

In conclusions, the runoff estimation for the Shipra river basin is hoped to contribute in hydrological analysis, water resources development and management and it's also solved the water sharing problems. The rainfall-runoff was successfully tested using Artificial Neural network (ANN) Model during this study. Satisfactory and reliable results were obtained with their Sum of Squares Error, Relative Error. One of the major weaknesses of ANN models is that they may fail to generate good estimates for extreme events. However, since the ANN model has the chance to be trained well for regular events it has higher chances of producing reliable results. Thus, it is very important to be able to identify the extreme events. This study demonstrates the usefulness of the Artificial Neural Network Model (ANN) model for the rainfall-runoff modeling at Shipra river basin.

\section{References}

Agarwal, A., Singh, R.D. (2004). Runoff modelling through back propagation artificial

neural network with variable rainfallrunoff data. Water Resources Management 18, 285-300

Garbrecht, J. D. (2006). Comparison of three alternative ANN designs for monthly rainfall-runoff simulation. Journal of Hydrologic Engineering 11 (5), 502505.

Green, W. H. and Ampt, G. A. (1911). Studies on soil physics. The flow of air and water through soils. Journal of Agriculture Science. (4). p. 1-24.

Hall, M. J., Minns, A.W. (1993). Rainfallrunoff modeling as a problem in artificial

intelligence: experience with a neural network. In: Proceedings 4th National Hydrological Symposium, British Hydrological Society, London, UK, pp. 5.51-5.57

Karunanithi, N., Grenney, W.J., Whitley, D., Bovee, K. (1994). Neural networks for river flow prediction. Journal of Computing in Civil Engineering 8 (2), 
201-220.

Kumar, V. and Rastogi R. A. (1989). Determination of direct runoff from a small agricultural watershed. $J$ of Agric. Engg. ISAE. 26(3):223-228.

Kumbhare, P. S. and Rastogi, R. A. (1984) Determination of surface runoff from Himalayan watershed using twoparameter conceptual model. In: 21st Annual Convocation of Indian Society of Agricultural Engineering, Indian Agriculture Research Institute, New Delhi.

Linsley, R. L. (1982) Rainfall-runoff models An overview in rainfall-runoff relationship. In: Proceedings of the International Symposium on RainfallRunoff Modelling, May, 18-21, p. 3-22.

Maidment, D. R. (1993) Handbook of Hydrology. 1st Edn. New York: McGraw Hill Publication.

Mcpherson, M. B. (1969). Some notes on the rational method of storm drain design. Tech. Memo. No. 6 ASCE, Water Resources Research Program, Harvard University, Cambridge, MA.

Nash, J. E. (1958). Determination of runoff from rainfall. Institute of Civil Engineering. (10). p. 163-184.

Saran, B., Kashyap, P. S., Singh, B. P., Singh V. K., and Vivekanand (2017). Daily Pan Evaporation Modelling in Hilly Region of Uttarakhand Using Artificial Neural Network Indian Journal of Ecology 44(3): 467-473

Singh, B. P., Kumar, P., Singh, V. K. and Mangal Yadav (2015) Rainfall prediction through artificial neural networks (ANNs): A soft computing approach. Progressive Research - An
International Journal, Volume 10 (Special-III): 1167-1173.

Singh, B. P., Kumar, P., Srivastava, T. and Singh, V. K. (2017) Estimation of Monsoon Season Rainfall and Sensitivity Analysis Using Artificial Neural Networks. Indian Journal of Ecology, 44 (Special Issue-5): 317-32.

Singh, V. K., Kumar, P., Singh, B. P. (2016) Rainfall-runoff modelling using Artificial Neural network. Indian Journal of Ecology 43(2): 436-442.

Singh, V. K., Singh, B. P., Kisi, O., Kushwaha, D. P. (2018). Spatial and multi-depth temporal soil temperature assessment by assimilating satellite imagery, artificial intelligence and regression-based models in arid area, Computers and Electronics in Agriculture 150: 205-219

Smith, J. and Eli, R.N., (1995) Neural-network models of rainfall-runoff process. Journal of Water Resources Planning and Management 121 (6), 499-508.

Srivastava, T., Kumar, P and Singh, B. P. (2017) Rainfall forecast of Kumarganj area using artificial neural network (ANN) models. Progressive Research An International Journal, Volume 12 (Special-I): 1375-1379.

Thirumalaiash, K. and Deo, M.C. (1998) River stage forecasting using neural networks. J. Hydrologic Engineering, 3(1): 26-32.

Tokar, A. S., Johnson, P.A., (1999) Rainfallrunoff modeling using artificial neural networks. Journal of Hydrologic Engineering 4 (3), 232-239.

Zealand, C. M., Burn, D. H. and Simonovic, S. P. (1999) Short term stream flow forecasting using artificial neural networks. J. Hydrology, 214: 32-48.

\section{How to cite this article:}

Ashish Krishna Yadav, Veerendra Kumar Chandola, Abhishek Singh and Bhaskar Pratap Singh. 2020. Rainfall-Runoff Modelling Using Artificial Neural Networks (ANNs) Model. Int.J.Curr.Microbiol.App.Sci. 9(03): 127-135. doi: https://doi.org/10.20546/ijcmas.2020.903.016 